\title{
Rapid Screening Analysis of Antioxidant Activities in Green Tea Products Using DPPH and FRAP
}

\author{
Vendra Setiawan ${ }^{1} *$, Sherlly Phangestu ${ }^{1}$, Agatha Grace Soetikno ${ }^{\prime}$, Angelina Arianti, Indrajati \\ Kohar $^{1}$ \\ ${ }^{1}$. Faculty of Pharmacy, Department of Pharmaceutical Chemistry, University of Surabaya, Surabaya, Indonesia.
}

\section{ARTICLE INFO}

Article

submission: 03

October 2021

Revision

submission: 09

November 2021

Acceptance for

publication: 18

November 2021

Keywords:

Antioxidant,

Camellia sinensis,

DPPH, FRAP

\section{ABSTRACT}

Introduction: Free radicals are formed inside and outside the body. Free radicals inside the zbody can be created in the cell compartments. The reactions are complex through the initiation, propagation, and termination stages. On the other hand, free radicals in the outer body can be formed from pollutions and environmental damage action. Excessive free radicals cause oxidative stress and use destructive cellular to affect health conditions. Antioxidants are known as essential agents in biological systems against diseases triggered by free radicals. One of the many antioxidants found in tea plants (Camellia sinensis) is polyphenols.

Objectives: to describe the rapid screening analysis of the antioxidant activity methods using DPPH and FRAP in green tea drink.

Methods: A colorimetry method was employed to evaluate the dominant antioxidant compound of the total phenolic and flavonoid content in two selected tea products. The total phenolic content was determined by utilizing the Folin-Ciocalteu reagent. While an aluminum colorimetric assay is applied to assess flavonoid content. Rapid screening of antioxidant activity using a spectrophotometric method is employed to determine IC50 values of tea extracts utilizing DPPH and FRAP.

Results: Their IC50 score are 76,35 to $213,20 \mathrm{pm}$ in loose leaves tea and 87,92 to 269,79 ppm in the teabag (DPPH method); and 9,88 until 26,95 ppm in loose leaves tea and 10,47 to $19,57 \mathrm{ppm}$ in the teabag (FRAP method).

Conclusions: The high total phenolic and flavonoid contents found in this experiment are in line with low IC50 values or in other words high antioxidant activities.

Keywords: Antioxidant, Camellia sinensis, DPPH, FRAP 


\section{Introduction}

Free radicals are atomic particles that have one or more unpaired electrons. A side effect of excessive free radicals causes oxidative changes. When excess free radicals are in the body, they will play a role in cell damage through the oxidation metabolism. It can cause shutting down respiration cells through oxidizing membrane lipid, protein, and DNA pathways (1). Free radicals as reactive oxygen species (ROS) can occur inside (endogen) or outside the body (exogen). Endogenous radicals (e.g., peroxyl (ROO•), hydroxyl $(\mathrm{OH} \bullet)$ ) are harmful and play a role in health and disease. Endogenous radicals are produced in cellular-compartments such as peroxisomes, cytosol, mitochondria, endoplasmic reticulum, plasma membrane, and lysosomes (2). The process is a complex series of chemical reactions. More details have been explained by Nandini Ghosh (2017). The formation of excessive exogenous radicals is the result of the involvement of human actions. Exogenous free radicals come from human actions that damage the environment and cause unhealthy lifestyles. They come from improper handling of industrial waste, increased motor vehicle fumes, land clearing by burning forests, excessive use of pesticides, and cigarettes smoke. Free radicals in foodstuffs can cause food deterioration. Chemical spoilage in food is marked by rancidity, change of color, flavor, and texture. It can cause deterioration of nutritional value and spoiled food (3). The reaction is spontaneous and is called autoxidation (1).

Open mindfulness of the threats of free radicals causes individuals to discover ways to neutralize free radicals through antioxidants. The Antioxidant is a helpful, economical, and convenient process. Antioxidants can donate electrons or hydrogen atoms to act as reducing agents. They are compounds that are capable of delaying, slowing, or inhibiting oxidation reactions in food and drugs whereas these compounds are easily oxidized so that other cells are protected from free radicals.

Base on their mechanism there are primary and secondary antioxidants. Primary antioxidants are also called chain-breaking antioxidants or scavenger antioxidants. Their action neutralizes radicals by donating electrons so that the radical compounds that have become stable cannot continue the propagation of the reaction, and the reaction chain is broken. Primary antioxidants are effective in the induction step and slow down the oxidation reaction. Examples of primary antioxidants are ascorbic acid, tocopherol, phenolic compounds such as gallic acid, and catechin. Secondary antioxidants prevent oxidation reactions by several mechanisms. The first mechanism inhibits initiation by oxidizing themselves. Secondary antioxidants can convert intermediate or final products into non-toxic products. For example, they prevent transition metal ions from participating in the reactions they catalyze.
Another secondary antioxidant's mechanism, such as ascorbic acid, encourages the rejuvenation of primary antioxidants by replenishing atom hydrogen (1).

Based on the source, antioxidants can be synthesized by chemicals or naturally found in animals, plants, and microorganisms. Some synthetic antioxidants have been made, such as BHA (butylated hydroxyanisole) and BHT (butylated hydroxytoluene). It is commonly used as a preservative in food manufacturing. Plants as herbs, spices, fruits, vegetables, oil, and tea groups, provide natural antioxidants such as tocopherols, and polyphenols compounds. Polyphenol compounds act as antioxidants and are one of the usual sources of polyphenols in tea (Camellia sinensis). Tea is one of the foremost well-known drinks in the world. Tea is divided into green tea, black tea, and oolong tea (4). Green tea contains higher polyphenol content than the others. Many industries produce dried tea leaves for brewing and dried tea leaves that are packed in tea bags. Teabag is a small, porous, heat-resistant, and rope-filled pouch bag. It usually contains small fractions of tea leaves, while the loose leaves tea is dried as whole leaves and packed in plastic wrap or canned.

Antioxidant activity is determined in many strategic assays. The first type of method was developed to direct the measurement of hydrogen and electron transfer. They are related to their scavenging capacity against specific radical species. They are known as the free radical scavenging method (1). one of the specific radical species which is the most frequently used is 2,2-diphenyl-1picrylhydrazyl (DPPH). It is based on the ability of phenol compounds to donate hydrogen atoms to DPPH free radicals. DPPH is the most common method to determine antioxidant capacity because it is fast, simple, accurate, low-costed, and sensitive $(5,6,7)$. DPPH is a stable chromogen-free radical whose purple color changes when the reaction occurs. It is measured at $522 \mathrm{~nm}$ on a visible spectrophotometer. On the other hand, antioxidant activity is also able to be measured by a reduction-oxidation reaction. The capability of antioxidants as reductants was applied to reduce various metal ions. Iron, copper and chromium are the most commonly used. The Ferric Reducing Antioxidant Power (FRAP) method is based on the ability of antioxidants in reducing ferri-tripyridyltriazine (Fe (III) TPTZ) to complex Ferro-TripyridylTriazine (Fe (II) TPTZ) (8). The aim of this study is to describe the rapid screening analysis of the antioxidant activity methods using DPPH and FRAP in green tea drink.

\section{Methods}

\section{Sample}

The samples consist of six brands of tea products, marketed in Indonesia. They are GM, WA, CB, GA, TT, and DT. The abbreviations showed the origin 
manufacturing of the green tea products which is from Ciwidey (Bandung), Pandaan (East Jawa), Pekalongan, Tegal, and Slawi (Central Jawa), respectively. They are all from Indonesia. The samples of this study are purchased at three supermarkets which are located in Tenggilis Mejoyo district, Surabaya. Each brand has two different types of tea products: green tea bags and loose leaves green tea.

\section{Chemical Reagents}

Ethanol 96\% (Technical Grade), Filter paper (Whatman \# 41, Maidstone England), demineralized water (University of Surabaya), Sodium hydroxide p.a., Gallic acid 98\% (MP Biomedicals, France), 2,2-diphenyl-1picrylhydrazyl (DPPH) p.a., 2,4,6-tripyridyl-s-triazine (TPTZ), Catechin Standart p.a. (Sigma Aldrich, St. Louis, Missouri, US). Aluminium chloride p.a., Folin- Ciocalteu reagent, Sodium carbonate p.a., Anhydrous Sodium acetate, Acetic acid, and Ferric chloride (Merck KGaA, Darmstadt, Germany).

\section{Equipment}

The equipment used was spectrophotometer UV-Vis (Hitachi U-2000, Tokyo, Japan), analytical balance (Sartorius, Japan), micropipettes (Socorex, Swiss), glasswares (cuvettes, beaker glasses, volumetric flask).

\section{Green Tea Extract}

Green tea from the teabag was taken out from the teabag and weighed $250 \mathrm{mg}$. accurately, in a $50 \mathrm{ml}$ beaker glass. On the other hand, $250 \mathrm{mg}$ of loose leaves green tea was also weighed accurately in a $50 \mathrm{ml}$ beaker glass. To each beaker glass, $25 \mathrm{ml}$ of boiling demineralized water was added and allowed to stand for 10 minutes. Each green tea extract was filtered using Whatman no. 41 filter paper to a $50,0 \mathrm{ml}$ volumetric flask. To the residue was added 20 $\mathrm{ml}$ boiling demineralized water and allowed to stand for another 10 mins. Then it was again filtered to the volumetric flask, and demineralized water was added to the mark $(50,0 \mathrm{ml})$.

The number of tea leaves in this study is more dilute than that of the daily use of green tea drink. It should be noted that it is varied considerably in daily use of green tea among different ethnic populations in the world. 2-3 g of tea in Japan and China are brewed in $100-150 \mathrm{~mL}$ hot water. American people drink $2.25 \mathrm{~g}$ of tea in $180-240 \mathrm{~mL}$ water (9).

\section{Total Phenolic Content}

$0,1 \mathrm{ml}$ green-tea extract was pipetted into a $10,0 \mathrm{ml}$ volumetric flask. Then $0,1 \mathrm{ml}$ of Folin- Ciocalteu reagent was added into the volumetric flask and allowed to stand in the dark for 5 minutes. Furthermore, $\mathrm{Na} 2 \mathrm{CO} 3$ solution $(7 \%, 2 \mathrm{ml})$ was added to the volumetric flask and allowed to stand in the dark for 30 minutes. After that, demineralized water was added to the volumetric flask up to a volume of $10,0 \mathrm{ml}$. The resulting blue solution was observed at the maximum wavelength $(702,2 \mathrm{~nm})$. Three replications were performed. The result was expressed as Gallic Acid Equivalent (GAE) mg per $100 \mathrm{mg}$ sample $(10,11)$.

\section{Total Flavonoid Content}

$1,0 \mathrm{ml}$ green tea extract was pipetted into a $10,0 \mathrm{ml}$ volumetric flask. Then $0,3 \mathrm{ml}$ of $5 \% \mathrm{NaNO} 2$ solution was added and allowed to stand for 6 minutes. After that, $0,3 \mathrm{ml}$ of $10 \% \mathrm{AlCl} 3$ solution was added and allowed to stand for another 6 minutes. Furthermore, 2,0 $\mathrm{ml}$ of $1 \mathrm{M} \mathrm{NaOH}$ solution was added to the flask, and then demineralized water was added up to the mark. The absorbance of the pink solution was observed at the maximum wavelength. $(507,5 \mathrm{~nm})$. Three replications were performed. The result was expressed as Catechin Equivalent (CE) mg per $100 \mathrm{mg}$ sample $(8,12)$.

\section{Measurement of Antioxidant Activity by DPPH Radical Scavenging Activity}

$1,0 \mathrm{ml}$ green tea extract was mixed with $3,0 \mathrm{ml} \mathrm{DPPH}$ solution and 1,0 $\mathrm{ml} 80 \%$ ethanol in a vial, and it was kept in the dark (incubating). The sample solution was observed for its absorbance at the maximum wavelength of $522,0 \mathrm{~nm}$. A mixture of 3,0 mL of DPPH solution and 2,0 ml of $80 \%$ ethanol was used as control. Three replications have been performed. The following equation calculates the percentage of inhibition:

$\%$ inhibition $=[1-\quad$ (absorbance of test solution blank absorbance )/(control absorbance) ]x 100\%

The $\%$ inhibition value of the various concentrations of the test solutions, a regression curve was made between the concentrations vs. \% inhibition. Then the regression equation for the curve is determined: $\mathrm{y}=\mathrm{bx}+\mathrm{a}$, where $\mathrm{y}=$ $\%$ inhibition, $\mathrm{x}=$ concentration of the test-solution, $\mathrm{a}=$ intercept, $\mathrm{b}=$ gradient. The IC50 value can be calculated quantitatively by entering $50 \%$ as y value in the regression equation

\section{Measurement of Antioxidant Activity with FRAP Assay}

FRAP solution was prepared by dissolving $186.94 \mathrm{mg}$ of anhydrous $\mathrm{Na}$ acetate in $1,6 \mathrm{ml}$ of acetic acid $(\mathrm{CH} 3 \mathrm{COOH})$ solution, and mineral-free water was added to make $100.0 \mathrm{ml}$ buffer acetate solution $(\mathrm{pH} \mathrm{3.6)}$. On the other hand, $0,15 \mathrm{~g}$ TPTZ is accurately weighed and dissolved in $40 \mathrm{mM} \mathrm{HCl}$ until it reaches a volume of 50.0 $\mathrm{ml}(10 \mathrm{mmol} / \mathrm{L}$ TPTZ solution). Then $0,27 \mathrm{~g}$ of $\mathrm{FeCl} 3$ $6 \mathrm{H} 2 \mathrm{O}$ was accurately weighed and dissolved in mineralfree water until it reached a volume of $50.0 \mathrm{ml}(20 \mathrm{mmol} / \mathrm{L}$ $\mathrm{FeCl} 36 \mathrm{H} 2 \mathrm{O}$ solutions). The final step was mixing and 
homogenizing $25.0 \mathrm{ml}$ of acetate buffer, 2,5 $\mathrm{ml}$ of TPTZ solution, and $2,5 \mathrm{ml}$ of $\mathrm{FeCl} 36 \mathrm{H} 2 \mathrm{O}$ solution (10:1:1) to produce FRAP reagent. 1,0 $\mathrm{ml}$ FRAP reagent was mixed with $1,0 \mathrm{ml}$ green tea extract. The mixture was then put into a vial and allowed to stand according to the obtained stable time. Next, the absorbance was measured at the maximum wavelength $(601,5 \mathrm{~nm})$. Three replications were performed. The percentage of antioxidant capacity is calculated as the following equation:

$$
\% \text { capacity }=[1-(10-\mathrm{Abs})] \times 100 \%
$$

The percentage value of the capacity of various concentrations of the test extract, a regression curve was made between the content vs. \% capacity. Then the regression equation for the curve is determined $y=b x+a$, where: $y=\%$ capacity, $x=$ concentration of test solution, a $=$ intercept, $\mathrm{b}=$ gradient. The IC50 value can be calculated quantitatively by entering $50 \%$ as $y$ in the regression equation (13).

\section{Result and Discussion}

People in the world have recognized green tea as beverages. People believed that Green tea consumption is able to increase health promotion. Moreover, tea ritual time worldwide has become a culture country such as Japan, China, Korea, and The United Kingdom. After harvesting the leaves, green tea is processed by inactivating the enzyme polyphenol oxidase. The enzyme is heat - labile. Thus, the steam process was used to prevent oxidation reaction in the leaves. This process produced green tea extract which is abundant in flavonoids as well as the polyphenols. Tea leaves as loose-leaves tea are rolled, dried, and packed. While in the teabag, the leaves have to undergo a reducing size before being packed $(9,14)$.

Polar or organic solvents such as methanol, ethanol, and acetone were often added to extract phenolic compounds, but Green tea leaves were only extracted with hot water in this study. This process is like serving tea in a drink. This process is quite effective because many of the polyphenolic components present in the vacuole can be simply extracted after the cell wall and membrane rupture. (15). The concentration of the extract in this study was 250 $\mathrm{mg} / 50,0 \mathrm{~mL}$ or $5000 \mu \mathrm{g} / \mathrm{mL}$, it was about a quarter of Japan's and China's serving or half of American's serving. The extracts in those servings are too concentrated for direct use in total phenolic, flavonoid, and antioxidant activity assay. Therefore, a dilution process was needed to facilitate the analysis process (9).

Total flavonoid contents as catechin equivalent were shown in table 1 . The total flavonoid contents of six brands products were 1,57 to $4,83 \mathrm{mg}$ in loose leaves tea and 2,83 to $5,61 \mathrm{mg}$ in teabag. The variation of the content was caused by many factors. It depends on the different age of the leaves when it was picked and how the leaves were processed such as fermentation, heating, and drying process. It affected their composition, especially flavonoids (14). As one of the subclass polyphenols, flavonoids have variations in substitution patterns of the hydroxyl groups. The total phenolic contents were expressed as gallic acid equivalent. This assay was based on the ability of the phenolic groups to be oxidized. This reaction makes Folin-Ciocalteu (contains phosphotungsticphosphomolybdic) reduce to molybdenum-tungsten. The total phenolic contents analyzed in this study were 3,70 to $10,14 \mathrm{mg}$ in loose leaves tea and 7,86 $\mathrm{mg}$ to $11,0 \mathrm{mg}$ in teabag as gallic acid equivalent.

Regression curve of Gallic Acid : y $=0,0913 \mathrm{x}+$ $0,0271 \mathrm{r} 2=0,9962$ Regression curve of Catechin : $\mathrm{y}=$ $0,018 \mathrm{x}+0,006 \mathrm{r} 2=0,9981$

Table 1. Total Phenol Content (TPC), Total Flavonoid Content (TFC), and Antioxidant Activity of Green Tea

\begin{tabular}{|c|c|c|c|c|}
\hline \multirow{2}{*}{ SAMPLE } & \multirow{2}{*}{$\begin{array}{c}\text { TPC }(\% \\
\text { GAE) }\end{array}$} & \multirow{2}{*}{$\begin{array}{c}\text { TFC } \\
(\% \mathbf{C E})\end{array}$} & \multicolumn{2}{|c|}{ IC50 (ppm) } \\
\cline { 4 - 5 } & & DPPH & FRAP \\
\hline GM$^{*}$ & $9,93 \pm 0,0729$ & $5,61 \pm 0,012$ & 150,85 & 28,96 \\
\hline GM & $6,76 \pm 0,1003$ & $4,83 \pm 0,056$ & 76,35 & 11,33 \\
\hline WA $^{*}$ & $11,00 \pm 0,1325$ & $3,70 \pm 0,013$ & 87,92 & 18,13 \\
\hline WA & $10,14 \pm 0,0505$ & $2,77 \pm 0,042$ & 188,34 & 10,07 \\
\hline CB $^{*}$ & $7,86 \pm 0,0747$ & $4,04 \pm 0,008$ & 370,69 & 19,57 \\
\hline CB & $3,70 \pm 0,0302$ & $2,31 \pm 0,007$ & 213,2 & 26,32 \\
\hline GA* & $9,03 \pm 0,0515$ & $3,69 \pm 0,013$ & 354,35 & 10,47 \\
\hline GA & $7,96 \pm 0,1453$ & $3,26 \pm 0,043$ & 200,75 & 11,96 \\
\hline TT* & $8,90 \pm 0,0421$ & $2,83 \pm 0,048$ & 241,45 & 26,95 \\
\hline TT & $8,51 \pm 0,0337$ & $2,34 \pm 0,014$ & 105,65 & 9,88 \\
\hline DT* & $10,51 \pm 0,1594$ & $2,95 \pm 0,018$ & 269,79 & 20,35 \\
\hline DT & $6,14 \pm 0,1230$ & $1,57 \pm 0,013$ & 180,02 & 12,28 \\
\hline
\end{tabular}

*Green tea bags

Figure 1. Total Phenol Content (TPC), Total Flavonoid Content (TFC), and Antioxidant Activity of Green Tea Extract

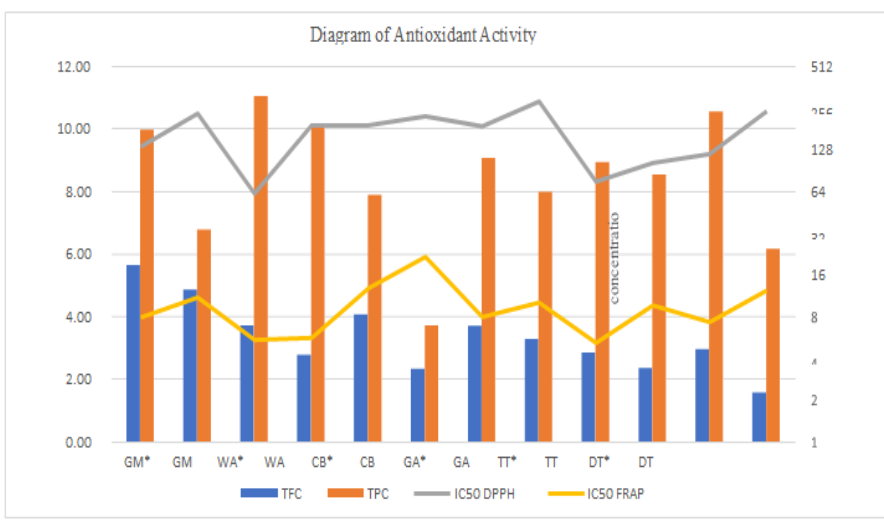


Antioxidant activity was represented in DPPH and FRAP methods as IC50. IC50 in the DPPH method can be defined as the effective concentration of the antioxidant compounds in tea that decreased initial DPPH concentration by $50 \%$ (1). It means that the DPPH method is used to determine radicals scavenging capacities. Antioxidant compounds in green tea donate their hydrogen atom (hydrogen atom transfer/ HAT) or transfer one electron to reduce radicals (single atom transfer/ SET). In the DPPH method, the combination of HAT and SET were performed for radicals scavenging determination (15). In the present study, antioxidants activities as IC50 were shown in table 1 or graph 1 . IC50 in the DPPH method ranges from76,35 to $213,20 \mathrm{ppm}$ in loose leaves tea and 87,92 to $269,79 \mathrm{ppm}$ in the green tea bag. Flavonoid groups in tea play a role in antioxidant activity. Hydroxyl substitution and flavonoid structure give various-level activity in antioxidants. The essential structure of flavonoids gives influential radicals scavenging activity such as the o-dihydroxy group in the B ring, C2-C3 double bond conjugated with a 4-keto group, and both $3-\mathrm{OH}, 5-$ $\mathrm{OH}$ group in combination with a 4-carbonyl function (16).

On the other hand, IC50 in the FRAP method means the effective concentration of the antioxidant compounds in tea that reduce $\mathrm{Fe} 3+$ to $\mathrm{Fe} 2+$ in FRAP by $50 \%$. It only utilized the SET mechanism. Six products in loose leaves tea showed IC50 from 9,88 until $26,95 \mathrm{ppm}$, and in the teabag was from 10,47 to $19,57 \mathrm{ppm}$. It was considered that other components in green tea could reduce metal ions in the redox mechanism, such as reducing sugar (17).

DPPH and FRAP could not be compared because they have different mechanisms to determine antioxidant activity. Their IC50 has a similar pattern (graph 1). The high TPC and TFC values in loose leaves and tea bags (graph 1) largely is in accordance with low IC50. Based on the important relationship between structure and effect of antioxidant activity, future studies are suggested.

\section{Conclusions}

Six products of green tea, which are marketed in Indonesia, have antioxidant activities which are from 76,35 to $213,20 \mathrm{ppm}$ in loose leaves tea and from 87,92 to $269,79 \mathrm{ppm}$ in the teabag (DPPH method) and from 9,88 to $26,95 \mathrm{ppm}$ in loose leaves tea and from 10,47 to $19,57 \mathrm{ppm}$ in the teabag (FRAP method). However, their antioxidant activities values using DPPH and FRAP have similar patterns. Flavonoid and polyphenol constituents have a role in antioxidant activity. It is shown that their high TFC and TPC values possess low IC50. Or in other words, the lower IC50 level, the higher the antioxidant activities.

\section{Acknowledegements}

The researchers would like to express their gratitude to The Research Institute and the Faculty of
Pharmacy of The University of Surabaya for their financial and laboratory support to all Laboratory Staffs who participated in this research.

\section{Conflict of Interest}

There is no conflict of interest.

\section{References}

1. Shahidi F, Zhong Y. Measurement of antioxidant activity. Journal of functional foods. 2015; 18:757-81. Available from: http://dx.doi.org/10.1016/j.jff.2015.01.047

2. Ghosh N, Das A, Chaffee S, Roy S, Sen CK. Reactive oxygen species, oxidative damage and cell death. Immunity and inflammation in health and disease: emerging roles of nutraceuticals and functional foods in immune support. Elsevier Inc.; 2017. 45-55 p. Available from: http://dx.doi.org/10.1016/B978-0-12-805417-8.00004-4 3. Antolovich M, Prenzler PD, Patsalides E, McDonald S, Robards K. Methods for testing antioxidant activity. Analyst. 2002;127(1):183-98.

4. Hilal Y, Engelhardt U. Characterisation of white tea Comparison to green and black tea. Journal of consumer protection and food safety. 2007;2(4):414-21.

5. Okta Dody Muzuka M, Danimayostu AA, Iswarin SJ. Uji Antioksidan Etosom Ekstrak Daun Jeruk Purut (Citrus hystrix D.C.) sebagai Anti Penuaan Kulit dengan Metode DPPH. Pharmaceutical journal of Indonesia. 2018;3(2):39-44.

6. Bajpai M, Pande A, Tewari SK, Prakash D. Phenolic contents and antioxidant activity of some food and medicinal plants. International journal of food sciences and nutrition. 2005 Jan 1;56(4):287-91.

7. Pourmorad F, Hosseinimehr SJ, Shahabimajd N. Antioxidant activity, phenol and flavonoid contents of some selected Iranian medicinal plants. African journal of biotechnology. 2006;5(11):1142-5.

8. John B, Sulaiman CT, George S, Reddy VRK. Total phenolics and flavonoids in selected medicinal plants from Kerala. International journal of pharmacy and pharmaceutical sciences. 2014;6(1):406-8.

9. Hu J, Webster D, Cao J, Shao A. The safety of green tea and green tea extract consumption in adults-Results of a systematic review. Regulatory Toxicology and Pharmacology. 2018 Jun 1;95:412-33.

10. Kim MJ, Kim JH, Kim JH, Kim YJ. Comparative studies on the antioxidant capacities and catechin profiles of conventional and organic green tea. Journal of the Korean Society for Applied Biological Chemistry. 2015;58(4):47580. Available from: http://dx.doi.org/10.1007/s13765-0150045-7

11. Ribarova F, Atanassova M. Total phenolics and flavonoids in Bulgarian fruits and vegetables. Journal of the university of chemical technology and metallurgy. 2005;40(3):255-60.

12. Roshanak S, Rahimmalek M, Goli SA. Evaluation of seven different drying treatments in respect to total flavonoid, phenolic, vitamin $\mathrm{C}$ content, chlorophyll, antioxidant activity and color of green tea (Camellia sinensis or C. assamica) 
leaves. Journal of food science and technology. 2016 Jan 1;53(1):721-9.

13. Kohar I, Qalbye A, Hadiyat MA, Allaf K. The Antioxidant Activities of The Extracts of Red Fruit (Pandanus conoideus Lam.) Pre-dried by Detente Instantanee Controlee (DIC). InProceeding 1st International Seminar on Natural Resources Biotechnology: From Local to Global 2015. Universitas Atma Jaya Yogyakarta.

14. Senanayake SN. Green tea extract: Chemistry, antioxidant properties and food applications-A review. Journal of functional foods. 2013 Oct 1;5(4):1529-41.

15. Nielsen SS. Food Analysis Fifth Edition. 5th ed. Food Analysis. West Lafayette: Springer Nature; 2017. 267 p.

16. Amić D, Davidović-Amić D, Bešlo D, Trinajstić $\mathrm{N}$. Structure-radical scavenging activity relationships of flavonoids. Croatica chemica acta. 2003 Apr 30;76(1):55-61.

17. Nakagawa M. Chemical Components and Taste of Green Tea Components of tea infusion and its taste. Japan Agricultural Research Quarterly.1975;9(3):156-60. 